\title{
The Upstream Determinants of Adult Obesity
}

\author{
Jeroen Lakerveld Joreintje Mackenbach
}

Department of Epidemiology and Biostatistics, VU Medical Center Amsterdam, Amsterdam, the Netherlands

\section{Keywords}

Physical activity · Dietary behaviours · Obesity · Adults · Upstream determinants

\begin{abstract}
Over-consumption of high-energy foods and a lack of physical activity are the main behavioural risk factors for people to develop obesity. These behaviours are influenced by a range of individual-level factors which are nested within contexts that contain influencing characteristics further upstream. In this paper, we define these upstream determinants. We also provide a historical background, summarise the current evidence base regarding these determinants across various types of environments and put them in perspective.

(C) 2017 The Author(s)

Published by S. Karger GmbH, Freiburg
\end{abstract}

\section{Introduction}

The increasing prevalence of obesity creates a growing burden for people, health care systems, and societies. The fundamental cause of obesity is an imbalance between calories consumed and calories expended [1]. Next to over-consumption of high-energy foods and lack of physical activity, there is also evidence that lack of sleep [2], high stress levels [3] and sedentary behaviour (i.e., sitting) [4] play a role. These 'obesogenic' behaviours can occur conjointly, in a dynamic way and with changing levels of intensity over the course of a day, year and lifetime. Obesogenic behaviours, in turn, are influenced by a range of individuallevel factors including biological and genetic factors, but also psychological factors such as knowledge, motivation and ability, which are nested within contexts that contain influencing characteristics further upstream. Attention to the upstream determinants (fig. 1) of obesity is increasing, as these determinants suggest entry-points for population-level action to prevent obesity and to reduce its prevalence and burden. In this paper, we define the upstream determinants of obesity and put them into perspective. 


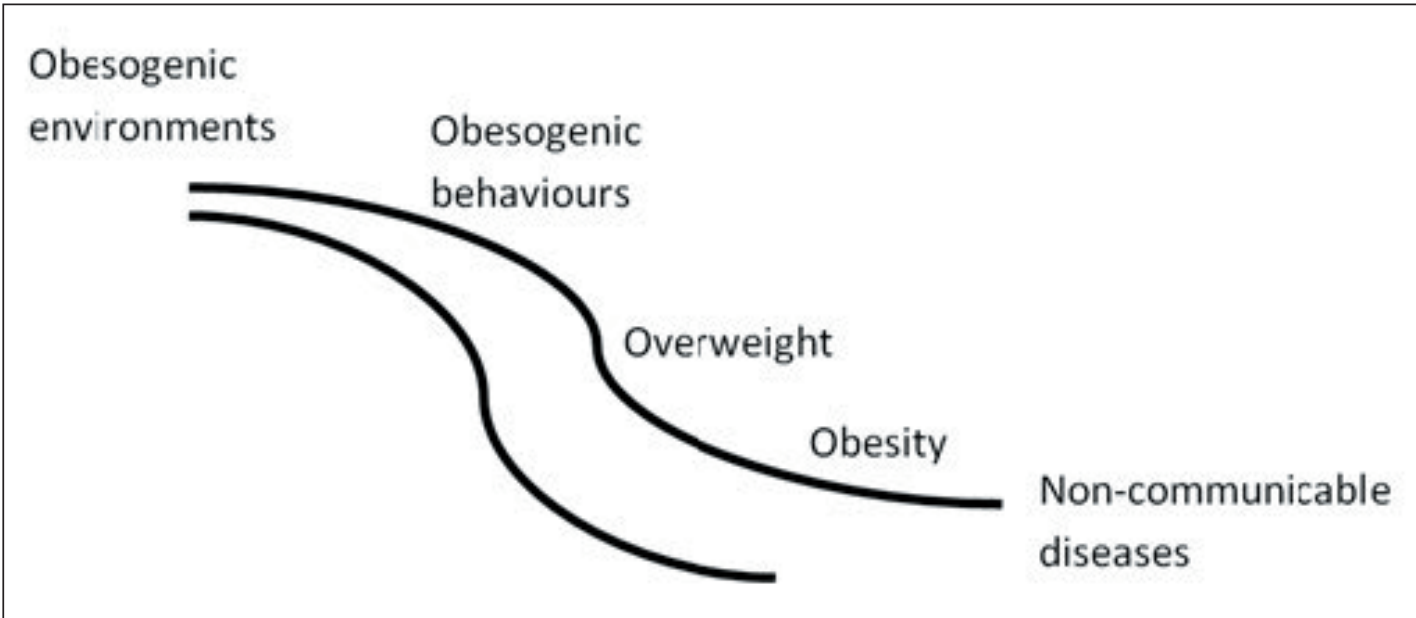

Fig. 1. A stream depicting the chronological order from upstream determinants to downstream diseases.

\section{Historical Developments Leading to Obesity}

In the process of domestication, we went from hunting and gathering food to planting and planning food production. We have advanced our methods to secure food resources and have created environments that make access to foods easier. Simultaneously, smart engineering obviated heavy manual work such that populations sit more and move less, despite busier schedules. In other words, we have adapted the context we live in. Up until a few decades ago, our energy intake and energy expenditure remained in balance, but in many developed countries we have reached a tipping point whereby excess energy has resulted in increased rates of obesity [5]. The relative price of calorie-dense foods and beverages has decreased in tandem with the observed rapid increase in consumption of energy-dense products [6] while physical activity can now be avoided almost everywhere and anytime, which has led to a decrease in our energy expenditure [7]. Geoffrey Rose has stated that 'the primary determinants of disease are mainly economic and social, and therefore its remedies must also be economic and social' [8]. Instead of focusing on a few high-risk individuals (for example those with a genetic predisposition), he pushed for a focus on the factors that pose a risk to entire populations, a significant one being the nature of the environments we live in.

\section{Defining Upstream Determinants of Obesity}

Upstream determinants of public health are usually defined as those overarching factors that are largely beyond the control of the individual and which have significant spill-over effects on other more proximal - or downstream - determinants of health. This concept draws on the idea of the lasting and far-reaching effects a polluted river has on populations living downstream. The term 'upstream' in this context stems from a popular analogy, 'moving upstream,' that is used to highlight the importance and relevance of primary prevention (see also 'Moving Upstream' below) [9]. The term is especially popular in the field of health disparities as 'it is unlikely that molecular etiological forces located within the individual will explain much of the heterogeneity in health and disease among social groups, places and times' [10]. An upstream determinant of obesity can be defined as any contextual characteristic (i.e., 
beyond individual-level characteristics) that influences obesogenic behaviours. Upstream determinants can take the form of tangible characteristics in the built or natural environments that surround us, such as cycling lanes, green space or fast-food outlets. Upstream determinants may also simultaneously manifest as - and interact with - less tangible features in our economic, political and socio-cultural environments [11]. Most conceptual frameworks assume a hierarchical arrangement of causal influences, with the primary cause originating at the cell level and contextual factors viewed as more distal and therefore less powerful risk factors [12]. However, it is important to acknowledge that causal pathways can also run from higher to lower levels, in which upstream determinants at the social and physical environmental levels influence and regulate lower-level factors such as individual behaviour, psychology and physiology. This is called downward causation [12].

\section{Identifying Upstream Determinants of Obesity}

\section{Moving Upstream}

While walking along the banks of a river, a passer-by notices that someone in the water is drowning. After pulling the person ashore, the rescuer notices another person in the river in need of help. Before long, the river is filled with drowning people, and more rescuers are required to assist the initial rescuer. Unfortunately, some people are not saved, and some victims fall back into the river after they have been pulled ashore. At this time, one of the rescuers starts walking upstream. 'Where are you going?' the other rescuers ask, disconcerted. The upstream rescuer replies, 'I'm going upstream to see why so many people keep falling into the river.' As it turns out, the bridge leading across the river upstream has a hole through which people are falling. The upstream rescuer realizes that fixing the hole in the bridge will prevent many people from falling into the river in the first place.

But what are the upstream determinants of obesogenic behaviours, obesity and the range of subsequent chronic non-communicable diseases we find further downstream? Neighbourhoods and communities have always been important units of research into upstream determinants of health outcomes like obesity [13]. Social factors such as segregation and social networks may have an impact on neighbourhood social interaction by shaping how people perceive their circumstances, influencing where and with whom they live, and shaping available resources. Similarly, the quality and content of the houses, infrastructure and facilities in neighbourhoods have a profound effect on behaviour and health outcomes. Yet, despite finding evidence of such relationships, we are only beginning to understand the causal pathways through which these contextual factors contribute to obesity. Upstream determinants are multiple, none operates in isolation, and they interact at different levels. Many types of research pose challenges, but research on the upstream determinants of obesity faces particular challenges due to the complexity of the causal pathways and the long time periods during which effects manifest themselves [14].

Upstream determinants of obesity are most often explored in the context of crosssectional observational studies. Randomised experimental studies allow for the possibility of isolating specific risk factors and exposing subjects at will, but in real life contextual factors do not occur in isolation, and it is often difficult to randomise individuals to new or changed environments. In spite of this, some examples do exist. For instance, in the study by Ludwig and colleagues [15], more than 4,000 women with children, residing in disadvantaged neighbourhoods with high poverty rates, were randomly assigned to one of three groups: a group that received vouchers that enabled them to move, a group that received vouchers to move to a wealthier neighbourhood and a group that received no vouchers. The opportunity to move to a neighbourhood with less poverty was associated with modest but potentially 
important reductions in the prevalence of (extreme) obesity 10 years later. Yet, the environment-obesity association is partly bidirectional, with a recent Mendelian randomisation study showing that BMI determines, at least in part and especially in women, several aspects of a person's socio-economic status [16].

The types of environments in which upstream determinants of obesity appear can be divided into physical (what is available), socio-cultural (what are the attitudes and beliefs), economic (what are the costs) and political (what are the 'rules') [11].

A number of systematic reviews conducted in the last decade show that there is little evidence of single physical environmental factors being strongly related to obesity [17-22]. Only two factors seemed to correlate consistently with weight status, namely urban sprawl and land-use mix. Evidence from the US has shown that residents living in sprawling suburbs with lower residential density are generally more likely to be obese. The purported pathway by which urban sprawl impacts obesity is that residents may be less inclined to opt for active modes of travel, have decreased access to facilities and engage less in social interaction [23]. Another relatively consistent finding is the link between land-use mix and obesity, such that a better mix of residential, commercial, institutional, industrial, recreational and agricultural land use is generally associated with less obesity. Again, this is likely to be due to increased levels of active modes of travel as more amenities are available in closer proximity.

The socio-cultural or social environment (i.e., the way we relate to each other) has also been studied extensively in relation to obesity. The most consistent upstream social determinant of obesity is socio-economic status and inequality: in higher-income countries, lower socio-economic status - and more inequality in general - is associated with higher levels of obesity in adults. (e.g. [24-27]). This may be explained by the lack of psycho-social and material resources of those with a lower socio-economic status; i.e., a lack of knowledge, social support, money and means [28]. The influence of other people, such as neighbours, family members, friends, colleagues and other 'social network' members, is also an important correlate of obesity risk. Christakis et al. [28] have shown that obesity spreads through social networks over time, mainly via siblings and friends. Explanations of the perceived effect of social networks include social contagion (whereby the network influences obesity-related behaviours via modelling), social capital (whereby a sense of belonging and social support influence obesity-related behaviours) and social selection (whereby an individual's network is a function of their weight) [29]. In a recent systematic review, we showed that the strongest social environmental correlates of obesity were, indeed, social capital and collective efficacy, but, in general, few social environmental factors were consistently related to adult obesity [30].

Studies on economic and political contextual correlates of obesity are sparser, although there is increasing evidence of an effect of the cost of a healthy diet [31]. Rao et al. [32] have investigated whether or not healthier foods and dietary patterns are more costly than less healthy options and concluded that this was indeed the case. The price difference of about USD 1.50/day/person represents the price difference for consuming a much healthier (e.g., a Mediterranean-type diet rich in fruit, vegetables, fish and nuts) versus a much less healthy overall diet (e.g., a diet rich in processed foods, meats and refined grains). Although health is considered to be a political matter [33], and many determinants of obesity require political action, there is a general lack of insight into the political upstream determinants of obesity. One study suggests that quality of governance is associated with obesity as increased stability and greater effectiveness of government provide more opportunities for policy makers to focus on key public health problems [34]. Another study linked civil law origin (comparing the British and the French models) to obesity in terms of the degree of regulation (e.g., market forces, consumer protections, lack of pricing freedom) [6]. World-wide, policy-driven approaches to reduce the prevalence of obesity are increasing considerably, but as yet, no government has implemented a comprehensive or effective set of policy approaches [35]. 
Lakerveld and Mackenbach: The Upstream Determinants of Adult Obesity

\section{Discussion}

The fragmentation of knowledge and studying upstream factors in isolation does not reflect the way the world works. Instead, it is the result of the analytic lens we impose - it is our natural predisposition when confronting a difficult problem to take things apart and treat the parts separately [36]. Obesity is a caused by a complex system of both downstream and upstream factors that interact with one another [37]. As such, there is growing recognition of the need to consider the multifaceted and complex nature of upstream influences on obesogenic behaviours [38]. A greater appreciation of systems theory and the use of system models may be helpful, but considerable challenges remain.

In contrast, efforts to prevent obesity and/or reduce population levels of obesity do not necessarily have to be complex. It can even be argued that obesity is, in principle, a simple problem and that obesity is only a complex problem because we make it a complex problem. Boldly speaking, if we want populations to live in free market economies and commercial environments in which they are constantly being challenged or even manipulated by food and other industries, have access to an abundance of places to sit and eat, while at the same time maintaining a normal weight, then things start to get complex. No single measure will be able to resolve the problem on its own, but a 'simplistic' view of the upstream causes of obesity may help us shape upstream solutions. For example, despite strong resistance from the beverage industry, several countries have adopted sugar-sweetened beverage taxation policies, simply because a decrease in the consumption of sugar-sweetened beverages is likely to prevent obesity or reduce obesity its prevalence. Such steps are difficult to implement and require decisiveness and courage, but sometimes compelling scientific evidence follows the action $[39,40]$.

By refraining from making political decisions about the prevention of obesity in populations, responsibility for the problem is shifted downstream to medical doctors that are confronted with the consequences of their patients' obesogenic lifestyles (i.e., treating sick individuals) [41]. Yet, there is an emerging movement of 'upstream doctors' that acknowledge that our health depends on social and environmental context [42]. These upstream doctors, along with a growing number of 'upstreamists' from a wide variety of disciplines, understand that obesity, diabetes and cardiovascular disease are for a large part the result of our busy modern schedules, the unhealthy food choices available in our stores and the way our neighbourhoods are designed. Individual-level approaches will continue to be important, but priority should be given to political actions that address our 'obesogenic environment' [5]. This is not a sprint, this is a marathon, and the levers for change are upstream.

\section{Acknowledgements}

This work builds on methods, results, and findings of collaborative efforts, particularly those within the SPOTLIGHT project www.spotlightproject.eu, and the Upstream Team www.upstreamteam.nl.

\section{Disclosure Statement}

There are no conflicts of interest to report. 


\section{References}

1 World Health Organization. Obesity and overweight. Factsheet. Updated June 2016. www.who.int/mediacentre/factsheets/fs311/en/ (last accessed May 19, 2017).

2 Patel SR, Hu FB: Short sleep duration and weight gain: a systematic review. Obesity 2008;16:643-653.

3 Ayanian JZ, Block JP, He Y, Zaslavsky AM, Ding L: Psychosocial stress and change in weight among US adults. Am J Epidemiol 2009;170:181-192.

4 Hu FB, Li TY, Colditz GA, Willett WC, Manson JE: Television watching and other sedentary behaviors in relation to risk of obesity and type 2 diabetes mellitus in women. JAMA 2003;289:1785-1791.

5 Swinburn B, Sacks G, Hall K, McPherson K, Finegood D, Moodie M, et al: The global obesity pandemic: shaped by global drivers and local environments. Lancet 2011;378:804-814.

6 Cutler DM, Glaeser EL, Shapiro JM: Why have Americans become more obese? J Econ Perspect 2003;17: 93-118.

7 Schmidhauser S, Eichler K, Brugger U: Environmental Determinants of Overweight and Obesity: Extended International Literature Review. Bern, Federal Office of Public Health, 2009.

8 Rose G: The Strategy of Preventive Medicine. Oxford, Oxford University Press, 1994.

9 Ardell DB: High Level Wellness: An Alternative to Doctors, Drugs, and Disease. Berkeley, Ten Speed Press, 1977.

10 Kaplan GA, Everson SA, Lynch JW: The contribution of social and behavioral research to an understanding of the distribution of disease: a multilevel approach; in Smedley BD, Syme SL (eds): Promoting Health: Intervention Strategies from Social and Behavioral Research. Washington, National Academies Press, 2000, pp 37-80.

11 Swinburn B, Egger G, Raza F: Dissecting obesogenic environments: the development and application of a framework for identifying and prioritizing environmental interventions for obesity. Prev Med 1999 ;29:563570.

12 Gehlert S, Sohmer D, Sacks T, Mininger C, McClintock M, Olopade O: Targeting health disparities: a model linking upstream determinants to downstream interventions. Health Aff 2008;27:339-349.

13 Diez-Roux a V, Nieto FJ, Muntaner C, Tyroler HA, Comstock GW, Shahar E, et al: Neighborhood environments and coronary heart disease: a multilevel analysis. Am J Epidemiol 1997;146:48-63.

14 Braveman PA, Egerter SA, Woolf SH, Marks JS: When do we know enough to recommend action on the social determinants of health? Am J Prev Med 2011;40(1 suppl 1):S58-66.

15 Ludwig J, Sanbonmatsu L, Gennetian L, Adam E, Duncan GJ, Katz LF, et al: Neighborhoods, obesity, and diabetes - a randomized social experiment. N Engl J Med 2011;365:1509-1519.

16 Tyresll J, Jones SE, Beaumont R, Astley CM, Lovell R, Yaghootkar H, et al: Height, body mass index, and socioeconomic status: Mendelian randomisation study in UK Biobank. BMJ 2016;352;i582.

17 Booth KM, Pinkston MM, Poston WSC: Obesity and the built environment. J Am Diet Assoc 2005;105(5 suppl 1):S110-S117.

18 Papas MA, Alberg AJ, Ewing R, Helzlsouer KJ, Gary TL, Klassen AC: The built environment and obesity. Epidemiol Rev 2007;29:129-143.

19 Feng J, Glass TA, Curriero FC, Stewart WF, Schwartz BS: The built environment and obesity: a systematic review of the epidemiologic evidence. Health Place 2010;16:175-190.

20 Durand CP, Andalib M, Dunton GF, Wolch J, Pentz MA: A systematic review of built environment factors related to physical activity and obesity risk: implications for smart growth urban planning. Obes Rev 2011;12:e173e182.

21 Ding D, Gebel K: Built environment, physical activity, and obesity: what have we learned from reviewing the literature? Health Place 2012;18:100-105.

22 Mackenbach JD, Rutter H, Compernolle S, Glonti K, Oppert J-M, Charreire H, et al: Obesogenic environments: a systematic review of the association between the physical environment and adult weight status, the SPOTLIGHT project. BMC Public Health 2014;14:233.

23 Croucher K, Wallace A, Duffy S: The influence of land use mix, density and urban design on health: a critical literature review. 2012. www.gcph.co.uk/assets/0000/3519/Review_of_infleunce_of_land_use_mix_density_ and_urban_design_on_health_final.pdf (last accessed May 19, 2017).

24 Sobal J, Stunkard AJ: Socioeconomic status and obesity: a review of the literature. Psychol Bull 1989;105: 260-275.

25 Monteiro CA, Moura EC, Conde WL, Popkin BM: Socioeconomic status and obesity in adult populations of developing countries: a review. Bull World Health Organ 2004;82:940-946.

26 Leal C, Chaix B: The influence of geographic life environments on cardiometabolic risk factors: a systematic review, a methodological assessment and a research agenda. Obes Rev 2011;12:217-230.

27 Goldman N: Social inequalities in health: disentangling the underlying mechanisms. Ann N Y Acad Sci 2001; 954:118-139.

28 Christakis NA, Fowler JH: The spread of obesity in a large social network over 32 years. N Engl J Med 2007; 357:370-379.

29 Powell K, Wilcox J, Clonan A, Bissell P, Preston L, Peacock M, et al: The role of social networks in the development of overweight and obesity among adults: a scoping review. BMC Public Health 2015;15:996. 
Lakerveld and Mackenbach: The Upstream Determinants of Adult Obesity

30 Glonti K, Mackenbach J, Ng J, Lakerveld J, Opper J-M, Bardos H, et al: Psychosocial environment: definitions, measures and associations with weight status - a systematic review (the SPOTLIGHT project). Obes Rev 2016; 17:96-107.

31 Drewnowski A, Darmon N: The economics of obesity: dietary energy density and energy cost. Am J Clin Nutr 2005;82(1 suppl):265S-273S.

32 Rao M, Afshin A, Singh G, Mozaffarian D: Do healthier foods and diet patterns cost more than less healthy options? A systematic review and meta-analysis. BMJ Open 2013;3:e004277.

33 Kickbusch I: The political determinants of health - 10 years on. BMJ 2015;350:h81.

34 Rabin BA, Boehmer TK, Brownson RC: Cross-national comparison of environmental and policy correlates of obesity in Europe. Eur J Public Health 2007;17:53-61.

35 Roberto CA, Swinburn B, Hawkes C, Huang TTK, Costa SA, Ashe M, et al: Patchy progress on obesity prevention: emerging examples, entrenched barriers, and new thinking. Lancet 2015;385:2400-2409.

36 Hamid TKA: Thinking in Circles About Obesity; Applying Systems Thinking to Weight Management. Heidelberg, Springer, 2009.

37 Vandenbroeck P, Goossens J, Clemens M: Foresight, Tackling Obesities: Future Choices - Building the Obesity System Map. London, Government Office for Science, 2007 www.gov.uk/government/uploads/system/uploads/ attachment_data/file/295154/07-1179-obesity-building-system-map.pdf (last accessed May 19, 2017).

38 Rutter H, Glonti K, Lakerveld J: The way ahead: where next for research into obesogenic environments? Obes Rev 2016;17:108-109.

39 HuFB: Resolved: There is sufficientscientific evidence that decreasing sugar-sweetened beverage consumption will reduce the prevalence of obesity and obesity-related diseases. Obes Rev 2013;14:606-619.

40 World Health Organization: Fiscal Policies for Diet and Prevention of Noncommunicable Diseases: Technical Meeting Report. 5-6 May 2015, Geneva, Switzerland, 2016. http://apps.who.int/iris/bits tream/10665/250131/1/9789241511247-eng.pdf?ua=1 (last accessed May 19, 2017).

41 Rose G: Sick individuals and sick populations. Int J Epidemiol 1985;14:32-38.

42 Manchanda R: The Upstream Doctors. TED Books, 2013. 